\title{
Clinical impact of targeted therapies in patients with metastatic clear-cell renal cell carcinoma
}

This article was published in the following Dove Press journal:

OncoTargets and Therapy

27 February 2014

Number of times this article has been viewed

\author{
Virginie Nerich ${ }^{1,2}$ \\ Marion Hugues' \\ Marie Justine Paillard ${ }^{3}$ \\ Laëtitia Borowski' \\ Thierry Nai' \\ Ulrich Stein ${ }^{3}$ \\ Thierry Nguyen Tan Hon ${ }^{3}$ \\ Philippe Montcuquet ${ }^{3}$ \\ Tristan Maurina ${ }^{3}$ \\ Guillaume Mouillet ${ }^{3}$ \\ François Kleinclauss ${ }^{2,4}$ \\ Xavier Pivot ${ }^{2,3}$ \\ Samuel Limat ${ }^{1,2}$ \\ Antoine Thiery-Vuillemin ${ }^{2,3}$ \\ 'Department of Pharmacy, University \\ Hospital, Besançon, France; ${ }^{2}$ Inserm \\ U645 EA-2284 IFR-133, University \\ of Franche-Comté, Besançon, France; \\ ${ }^{3}$ Department of Medical Oncology, \\ ${ }^{4}$ Department of Urology, University \\ Hospital, Besançon, France
}

Correspondence: Virginie Nerich Department of Pharmacy, University Hospital, Boulevard Fleming, 25030 BESANCON, Cedex, France $\mathrm{Tel}+3338 \mathrm{I} 668090$

Fax +33381668696

EmailvInerich@chu-besancon.fr
Introduction: The aim of this retrospective clinical study was to assess, in the context of the recent evolution of systemic therapies, the potential effect of targeted therapies on overall survival (OS) of patients with metastatic clear-cell renal cell carcinoma (mccRCC) in daily practice.

Patients and methods: All consecutive patients with histologically confirmed mccRCC who received systemic therapy between January 2000 and December 2010 in two oncology treatment centers in our Franche-Comté region in eastern France were included in the analysis. The primary end point was OS. The analysis of prognostic factors was performed using a two-step approach: univariate then multivariate analysis with a stepwise Cox proportional hazards regression model.

Results: For the entire cohort of 111 patients, the median OS was 17 months (95\% confidence interval [CI]; 13-22 months) and the two-year OS was 39\%. Three prognostic factors were independent predictors of long survival: prior nephrectomy (hazard ratio $=0.38$ [0.22-0.64], $P<0.0001$ ); systemic therapy by targeted therapy (hazard ratio $=0.50[0.31-0.80], P=0.005$ ); and lack of liver metastasis (hazard ratio $=0.43$ [0.22-0.82], $P=0.002$ ). Median OS was 21 months [14-29 months] for patients who received at least one targeted therapy compared with 12 months [7-15 months] for patients who were treated only by immunotherapy agents $(P=0.003)$.

Conclusion: Our results suggest that targeted therapies are associated with improved OS in comparison with cytokines, which is in line with other publications.

Keywords: angiogenesis, immunotherapy, metastatic renal cell carcinoma, mTOR, survival, targeted therapy

\section{Introduction}

Renal cell cancer (RCC) represents 3\% of all newly diagnosed cancers, with 11,080 cases, causing 3,840 deaths (2.6\% of all cancers), in France in $2011 .^{1}$ Among urologic cancers, it is the third most frequent after prostate and bladder cancers. ${ }^{2}$ Clear-cell carcinomas account for roughly $75 \%-80 \%$ of RCC and are associated with a worse prognosis than papillary or chromophobe histology. ${ }^{3,4}$ Other factors are associated with poor prognosis and may increase the risk of disease recurrence, ie, advanced tumor stage, positive regional node involvement, high Fuhrman nuclear grade, presence of tumor necrosis, presence of microvascular invasion, and poor performance status..$^{5-8}$

Surgical resection of the primary renal tumor is the current standard treatment for localized or locally advanced RCC. ${ }^{5-9}$ Despite nephrectomy, recurrence of cancer with distant metastases occurs in approximately $20 \%-40 \%$ of patients. ${ }^{10}$ Approximately $25 \%$ of patients with RCCs present with metastatic disease at initial diagnosis. ${ }^{11}$ Even with metastases, nephrectomy may be part of standard treatment. ${ }^{11,12}$

Management of metastatic clear-cell renal cell carcinoma (mccRCC) has undergone a transformation in the last decade. Novel targeted therapies have considerably 
expanded the number of treatment options for this indication. Previously, systemic treatment was limited to cytokine therapies with interleukin- 2 or interferon- $\alpha$ as mccRCC is largely resistant to chemotherapy. ${ }^{13}$ One exciting development in mccRCC research has been a better understanding of the molecular pathogenesis of clear-cell renal cell carcinoma. It involves inactivation of the von Hippel-Lindau (VHL) tumor suppressor gene. Normally, $V H L$ encodes a protein that is a component of a ligase for the hypoxia-inducible factor. During $V H L$ inactivation, hypoxia-inducible factor upregulates the transcription of multiple hypoxia-inducible genes, including those that promote angiogenesis and cellular proliferation. ${ }^{14,15}$ Tyrosine kinase receptors and their ligands have been shown to play an important role in tumor growth and angiogenesis. Inhibition of vascular endothelial growth factor (VEGF) signaling through the use of antibodies or VEGFR antagonists has demonstrated potent antitumor effects that might be used to circumvent resistance to classical anticancer agents. ${ }^{16}$ Besides, other non-VHL pathways may affect the development of RCC; for example, abnormal functioning of the mammalian target of rapamycin (mTOR) pathway. ${ }^{17}$ So far, seven targeted therapies (through inhibition of angiogenesis or the mTOR pathway) have been evaluated in randomized controlled Phase III clinical trials of patients with mccRCC and, subsequently, approved by regulatory authorities. ${ }^{18-24}$ These targeted agents have revolutionized the treatment of mccRCC and have largely surpassed immunotherapy as the first-line standard of care.

This recent evolution of mccRCC systemic management justifies the aim of our study, which was to assess, in daily practice, the impact of targeted therapies on overall survival (OS) of patients with mccRCC in comparison with more classical immunotherapy. In order to do this, the prognostic factors of OS were sought using a two-step approach. The secondary aim of this study was to assess first-line systemic therapy time to treatment failure (TTF) and the impact of its duration on OS.

\section{Patients and methods}

\section{Patients and treatment}

From January 2000 to December 2010, all consecutive patients with histologically confirmed mccRCC who received systemic therapy in two main oncology treatment centers of our region (University Hospital and Polyclinique of FrancheComté of Besançon) were included in the analysis. They were identified on the basis of $\mathrm{BPC}^{\circledR}$ software (University Hospital, Besançon, France), a computerized physician order entry system. This software is capable of tracking injectable and oral chemotherapy and targeted therapy prescriptions according to the tumor. Baseline demographics, clinical history, laboratory findings, and treatments were retrospectively collected according to the medical records and BPC software. Two cohorts of patients were defined according to their systemic therapies:

1. "targeted therapy" cohort, including patients who received at least one targeted therapy, ie, antiangiogenic (sunitinib, bevacizumab, sorafenib) or mTOR inhibitor (everolimus, temsirolimus);

2. "immunotherapy" cohort, including patients who were treated by immunotherapy, ie, interleukin-2 or interferon- $\alpha$, without targeted therapy.

Patients were classified according to Memorial SloanKettering Cancer Center (MSKCC) prognostic risk as favorable risk group (zero risk factor), intermediate risk group (one or two risk factors), and poor risk group (three or more risk factors). ${ }^{25,26}$ The risk factors included: interval less than 1 year between the date of diagnosis to the start of systemic therapy; low performance status with Karnofsky performance status $<80 \%$; an elevated serum lactate dehydrogenase (1.5 times the upper limit of normal); a high corrected serum calcium level (greater than the upper limit of normal); and anemia (hemoglobin level at the lower limit of normal).

\section{Setting}

Besançon University Hospital is the referent regional center in cancerology for the Franche-Comté region in eastern France (1.2 million of habitants). In 2012, in our region, 6,437 patients with cancer (138 patients with RCC) had been treated by systemic therapy (chemotherapy and/or targeted therapy), ie, 3,793 patients in University hospital or in Polyclinique de Franche-Comté (89 patients with RCC).

\section{Response assessments}

Clinical benefit and toxicity of the systemic therapies were evaluated by the oncologist at each visit. Imaging assessments of treatment efficacy were performed according to the metastatic sites by bone scan, computerized tomography, magnetic resonance imaging, positron emission tomography, or ultrasonography.

\section{Primary endpoint}

The primary endpoint was OS, defined as the time from initiation of first-line systemic therapy to death from any cause or to last follow-up for survivors. Patients alive on August 31, 2012, were censored. Median OS with its 95\% confidence interval (CI) and two-year OS were calculated using the Kaplan-Meier method. 
Several potential prognostic factors were studied to determine their impact on OS. They included:

- patient characteristics (age: $<60$ years versus $\geq 60$ years, $<65$ years versus $\geq 65$ years, $<70$ years versus $\geq 70$ years; sex: male versus female)

- prior nephrectomy (yes versus no)

- metastases: at presentation (yes versus no); $\geq$ two metastatic sites (yes versus no); lung metastasis (yes versus no); bone metastasis (yes versus no); lymph node metastasis (yes versus no); liver metastasis (yes versus no); other metastasis (yes versus no)

- metastasectomy (yes versus no)

- systemic therapy (targeted therapy versus immunotherapy)

The analyses of prognostic factors were performed using a two-step approach. Firstly, the association of potential prognostic factors with OS was examined by univariate analysis, using the logrank test. Quantitative and qualitative variables were transformed, whenever possible, into dichotomic variables using different successive cutoff points. Secondly, all variables with a $P$-value $<0.15$ in univariate analysis were entered in a stepwise Cox proportional hazards regression model. The results of univariate and multivariate analyses are presented with hazard ratio, $95 \% \mathrm{CI}$, and $P$-value.

One potential prognostic factor, MSKCC risk group (and its risk factors), was not included in these analyses because data for more than $10 \%$ of patients was lacking. However, descriptive analyses of OS were performed.

\section{Secondary endpoints}

The secondary endpoints were first-line systemic therapy TTF and the impact of its duration on OS. TTF was defined as the time from initiation of systemic therapy to the date of disease progression (ie, the date of the visit with the oncologist who confirmed the progression), start of a new line of systemic therapy treatment, or death by any cause. Patients remaining on treatment at the time of analysis were censored. TTF was analyzed using the Kaplan-Meier method.

\section{Statistical analysis}

Between our two cohorts, qualitative and quantitative variables were respectively compared by Fisher's exact test or chi-square test and nonparametric Mann-Whitney test. Continuous variables were described by mean \pm standard deviation and median (first quartile-third quartile), and qualitative variables by the size and percent rate.
All tests were two-tailed and significant at an alpha threshold of 5\% ( $P$-value). Statistical analysis was performed with $\mathrm{SAS}^{\circledR}$ software version 9.3 (SAS Institute Inc, Cary, NC, USA).

\section{Results Patient population}

From January 2000 to December 2010, a total of 111 patients with mccRCC received systemic therapy. Only 28 patients (25\%), making up the "immunotherapy" cohort, were given immunotherapy, and the other 83 patients (75\%) were included in the "targeted therapy" cohort. Patient characteristics at presentation and at metastatic diagnosis are presented in Table 1. The two cohorts were similar, except for the age of patients at metastatic diagnosis (mean age of $65 \pm 11$ years for patients of the "targeted therapy" cohort compared with $59 \pm 11$ years for patients of the "immunotherapy" cohort $[P=0.02])$. Approximately $80 \%$ of patients had undergone a prior nephrectomy, $20 \%$ were favorable MSKCC risk group, and 64\% were metastatic at diagnosis. Among them, 66 patients (59\%) had one metastatic site. The most common sites of metastases were the lungs (in $63 \%$ of patients), bone (in $26 \%$ of patients), lymph nodes (in $18 \%$ of patients), liver (in $15 \%$ of patients), and other sites (in $32 \%$ of patients).

\section{Follow-up and treatment}

For the entire cohort of 111 patients, the mean follow-up time after treatment initiation was $23 \pm 19$ months (median: 17 months [7-31 months]). The median of treatment lines also differs between the two cohorts: three (two to four) for patients of the "targeted therapy" cohort (first-line systemic therapy with antiangiogenic [80\%], mTOR inhibitor [12\%]) compared with one (one to two) for the "immunotherapy" cohort (first-line systemic therapy with immunotherapy [86\%] or immunotherapy plus chemotherapy [3\%]) $(P<0.0001)$.

Tables 2 and 3 present the systemic therapy according to the line-treatment for "immunotherapy" cohort and "targeted therapy" cohort, respectively.

\section{Overall survival}

Out of 111 patients of the entire cohort, a total of 91 patients died. Median OS was 17 months (95\% CI: [13-22 months]) and the two-year OS was 39\% (Figure 1A).

Univariate analysis indicated that seven potential prognostic factors were significantly associated with longer OS: prior nephrectomy $(P<0.0001)$; lack of liver metastasis $(P=0.0007)$; systemic therapy by targeted therapy $(P=0.003)$; lack of metastasis at presentation $(P=0.006)$; lack of lung 
Table I Demographic and baseline disease characteristics of patients at initial and metastatic diagnoses

\begin{tabular}{|c|c|c|c|c|}
\hline & $\begin{array}{l}\text { Entire } \\
\text { cohort } \\
\text { n=I I I }\end{array}$ & $\begin{array}{l}\text { "Immunotherapy" } \\
\text { cohort } \\
\mathbf{n = 2 8}\end{array}$ & $\begin{array}{l}\text { "Targeted } \\
\text { therapy" cohort } \\
n=83\end{array}$ & $P$-value \\
\hline \multicolumn{5}{|l|}{ At presentation } \\
\hline Age, years & & & & 0.07 \\
\hline Mean \pm SD & $61 \pm 12$ & $57 \pm 11$ & $62 \pm 11$ & \\
\hline Median (range) & 61 (26-88) & $60(36-73)$ & $63(26-88)$ & \\
\hline$<60, \mathrm{n}(\%)$ & $46(4 I)$ & $13(46)$ & $33(40)$ & 0.66 \\
\hline$<65, \mathrm{n}(\%)$ & $69(62)$ & $20(7 \mathrm{I})$ & $49(59)$ & 0.27 \\
\hline$<70, \mathrm{n}(\%)$ & $83(75)$ & $23(82)$ & $60(72)$ & 0.45 \\
\hline Sex, n (\%) & & & & 0.10 \\
\hline Male & $76(69)$ & $23(82)$ & $53(64)$ & \\
\hline Female & $35(3 \mathrm{I})$ & $5(18)$ & $30(36)$ & \\
\hline Prior nephrectomy, n (\%) & $89(80)$ & $22(79)$ & $67(8 I)$ & 0.79 \\
\hline Metastases, n (\%) & 7I (64) & $18(64)$ & $53(64)$ & 1.00 \\
\hline \multicolumn{5}{|l|}{ At metastatic diagnosis } \\
\hline Age, years & & & & 0.02 \\
\hline Mean \pm SD & $63 \pm 12$ & $59 \pm 11$ & $65 \pm 11$ & \\
\hline Median (range) & $63(27-88)$ & $61(36-75)$ & $64(27-88)$ & \\
\hline$<60, \mathrm{n}(\%)$ & $4 \mid(37)$ & $13(46)$ & $28(34)$ & 0.26 \\
\hline$<65, \mathrm{n}(\%)$ & $61(55)$ & $18(64)$ & $43(52)$ & 0.28 \\
\hline$<70, \mathrm{n}(\%)$ & $74(66)$ & $22(79)$ & $52(63)$ & 0.17 \\
\hline MSKCC risk group, $\mathrm{n}(\%)^{*}$ & & & & 0.77 \\
\hline Favorable & $22(23)$ & $4(20)$ & $18(24)$ & \\
\hline Intermediate & $66(70)$ & $16(80)$ & $50(68)$ & \\
\hline Poor & $6(7)$ & $0(0)$ & $6(8)$ & \\
\hline $\begin{array}{l}\text { Interval less than I year between the date of diagnosis } \\
\text { to the start of systemic therapy, } \mathrm{n}(\%)\end{array}$ & $75(68)$ & $17(6 \mid)$ & $58(70)$ & 0.48 \\
\hline Karnofsky performance status $<80 \% *, n(\%)$ & II (I2) & $3(15)$ & $8(11)$ & 0.70 \\
\hline LDH level > I.5 ULN*, n (\%) & $I(I)$ & $0(0)$ & $\mathrm{I}(\mathrm{I})$ & 0.60 \\
\hline Corrected calcium level > ULN, ${ }^{*}$ n (\%) & $7(8)$ & $0(0)$ & $7(10)$ & 0.34 \\
\hline Anemia, n (\%) & $16(17)$ & $2(10)$ & $14(19)$ & 0.51 \\
\hline Number of metastases, $\mathrm{n}(\%)$ & & & & 0.06 \\
\hline Mean \pm SD & $1.5 \pm 0.8$ & $1.7 \pm 0.8$ & $1.5 \pm 0.8$ & \\
\hline Median (range) & $I(I-5)$ & $2(1-4)$ & $I(I-5)$ & \\
\hline$\geq 2$ metastatic sites, $n$ (\%) & $45(4 I)$ & $16(57)$ & $29(35)$ & 0.05 \\
\hline Lung metastasis, n (\%) & $70(63)$ & $21(75)$ & $49(59)$ & 0.18 \\
\hline Bone metastasis, n (\%) & $29(26)$ & $8(29)$ & $21(25)$ & 0.80 \\
\hline Lymph node metastasis, n (\%) & $20(18)$ & $4(14)$ & $16(19)$ & 0.78 \\
\hline Liver metastasis, n (\%) & $17(15)$ & $4(14)$ & $13(16)$ & 0.86 \\
\hline Other metastasis, n (\%) & $35(32)$ & $10(36)$ & $25(30)$ & 0.64 \\
\hline Metastasectomy, n (\%) & $23(2 \mathrm{I})$ & $5(18)$ & $18(22)$ & 0.79 \\
\hline
\end{tabular}

Note: *Lack of data.
Abbreviations: LDH, lactate dehydrogenase; MSKCC, Memorial Sloan-Kettering Cancer Center; SD, standard deviation; ULN, upper limit of normal.

Table 2 Systemic therapy according to the line-treatment for "immunotherapy" cohort

\begin{tabular}{|c|c|c|c|c|}
\hline \multirow{2}{*}{$\begin{array}{l}\text { Metastatic } \\
\text { line-treatment }\end{array}$} & \multirow{2}{*}{$\begin{array}{l}\text { Number of } \\
\text { patients (\%) }\end{array}$} & \multicolumn{3}{|c|}{ Systemic treatment } \\
\hline & & Immunotherapy ${ }^{\mathrm{a}}$ & $\begin{array}{l}\text { Immunotherapy } \\
\text { plus chemotherapy }\end{array}$ & Chemotherapy \\
\hline I & $28(100)$ & $24(86)$ & I (3) & $3(I I)$ \\
\hline 2 & $12(100)$ & $3(25)$ & 1 & $9(75)$ \\
\hline 3 & $4(100)$ & 1 & 1 & $4(100)$ \\
\hline 4 & $2(100)$ & I & 1 & $2(100)$ \\
\hline
\end{tabular}

Notes: ${ }^{a}$ Interleukin-2 plus interferon- $\alpha$; binterferon- $\alpha$ plus vinblastine; ${ }^{c}$ vinblastine or dacarbazine or FOLFOX or gemcitabine or fluorouracil. 
Table 3 Systemic therapy according to the line-treatment for "targeted therapy" cohort

\begin{tabular}{|c|c|c|c|c|c|}
\hline \multirow{2}{*}{$\begin{array}{l}\text { Metastatic } \\
\text { line-treatment }\end{array}$} & \multirow{2}{*}{$\begin{array}{l}\text { Number of } \\
\text { patients (\%) }\end{array}$} & \multicolumn{4}{|c|}{ Systemic treatment } \\
\hline & & Antiangiogenic $^{\mathbf{a}}$ & mTOR inhibitor & Immunotherapy $^{c}$ & Chemotherapy $^{d}$ \\
\hline I & $83(100)$ & $66(80)$ & $10(12)$ & $6(7)$ & $I(I)$ \\
\hline 2 & $69(100)$ & $31(45)$ & $37(54)$ & I & $I(I)$ \\
\hline 3 & $47(100)$ & $31(66)$ & $14(30)$ & I (2) & $\mathrm{I}(2)$ \\
\hline 4 & $23(100)$ & $12(52)$ & $7(3 I)$ & I (4) & $3(13)$ \\
\hline 5 & $7(100)$ & $2(28)$ & 1 & 1 & $5(72)$ \\
\hline 6 & $3(100)$ & 1 & $2(67)$ & I (33) & I \\
\hline 7 & $I(100)$ & I & 1 & 1 & $I(100)$ \\
\hline
\end{tabular}

Notes: aSunitinib or sorafenib or bevacizumab \pm interferon- $\alpha$; ${ }^{b}$ temsirolimus or everolimus; cinterleukin-2; ${ }^{d}$ vinblastine or cyclophosphamide or gemcitabine.

Abbreviation: mTOR, mammalian target of rapamycin.

metastasis $(P=0.08)$; one metastatic site $(P=0.02)$; and presence of lymph node metastasis ( $P=0.13$ ) (Table 4). Median OS was 21 months (14-29 months) for patients of the "targeted therapy" cohort compared with 12 months (7-15 months) for patients of the "immunotherapy" cohort (hazard ratio $=0.52$

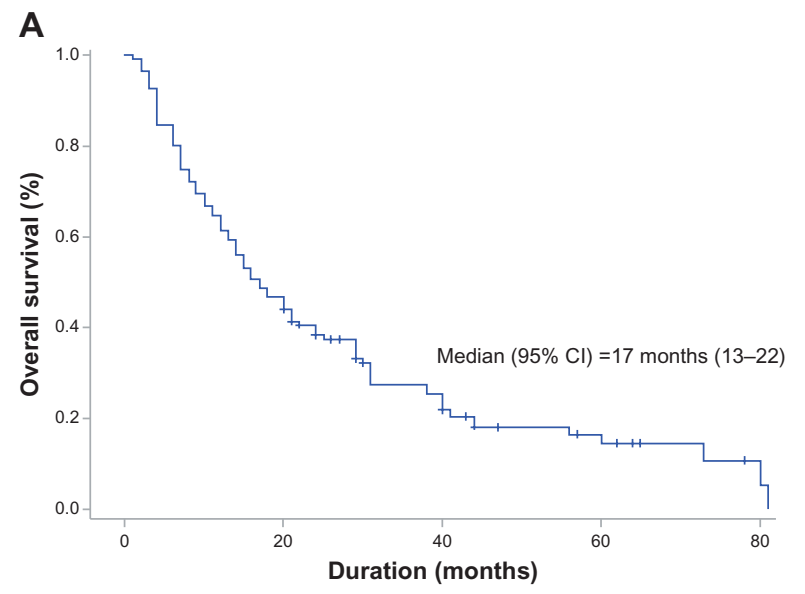

C

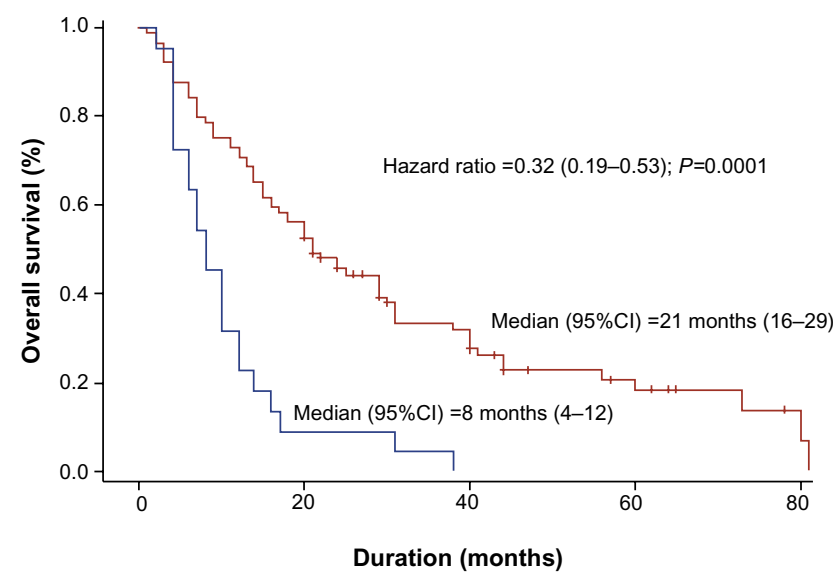

[0.33-0.81], $P=0.003$ ) (Figure 1B). Median OS was 21 months (16-29 months) for patients with prior nephrectomy compared with 8 months (4-12 months) for patients without prior nephrectomy (hazard ratio $=0.32$ [0.19-0.53], $P<0.0001$ ) (Figure 1C). All 40 patients without metastasis at

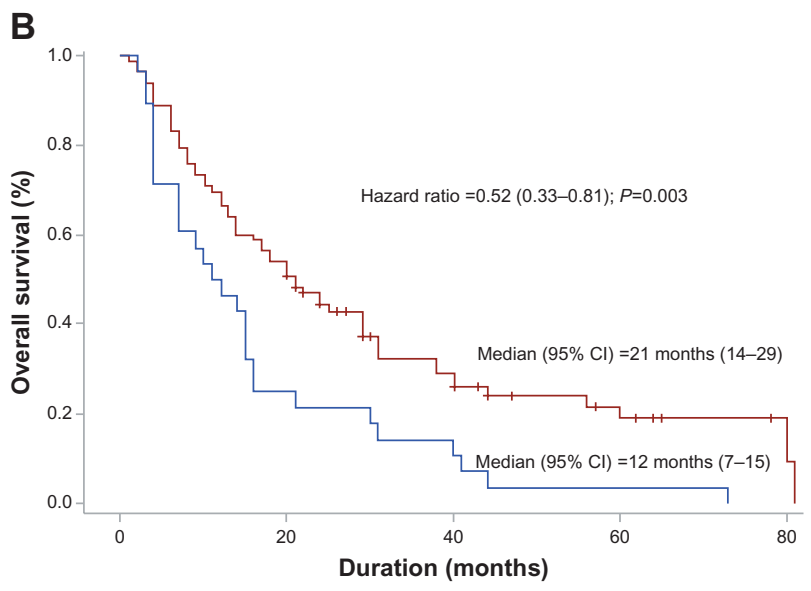

D

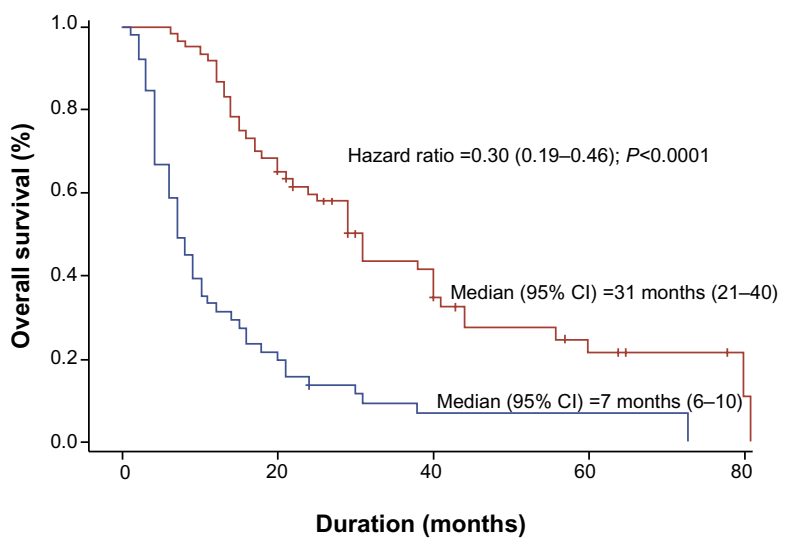

Figure I Kaplan-Meier estimates of overall survival.

Notes: (A) OS for the entire cohort. (B) OS according to the systemic therapy: "targeted therapy" (in red) versus "immunotherapy" (in blue). (C) OS according to prior nephrectomy: yes (in red) versus no (in blue). (D) OS according to the first-line systemic therapy time to treatment failure: $<6$ months (in blue) versus $\geq 6$ months (in red). Abbreviations: $\mathrm{Cl}$, confidence interval; OS, overall survival. 
Table 4 Univariate analysis of potential prognostic factors of overall survival

\begin{tabular}{|c|c|c|c|c|c|}
\hline \multirow[t]{2}{*}{ Potential prognostic factors } & \multicolumn{2}{|c|}{ Number of patients } & \multirow{2}{*}{$\begin{array}{l}\text { Median OS (months) } \\
\text { with } 95 \% \mathrm{Cl}\end{array}$} & \multirow{2}{*}{$\begin{array}{l}\text { Hazard ratio } \\
\text { with } 95 \% \mathrm{Cl}\end{array}$} & \multirow[t]{2}{*}{$P$-value } \\
\hline & Died & Total & & & \\
\hline Sex & & & & & 0.25 \\
\hline Male & 62 & 76 & $16(|2-2|)$ & $1.30(0.83-2.05)$ & \\
\hline Female & 29 & 35 & $29(12-38)$ & & \\
\hline Prior nephrectomy & & & & & $<0.0001$ \\
\hline Yes & 69 & 89 & $21(16-29)$ & $0.32(0.19-0.53)$ & \\
\hline No & 22 & 22 & $8(4-12)$ & & \\
\hline Age at metastatic diagnosis, years & & & & & 0.93 \\
\hline$<60$ & 35 & 41 & $16(11-29)$ & $0.98(0.64-1.50)$ & \\
\hline$\geq 60$ & 56 & 70 & $17(12-24)$ & & \\
\hline$<65$ & 51 & 61 & $16(11-25)$ & $1.09(0.72-1.66)$ & 0.68 \\
\hline$\geq 65$ & 40 & 50 & $17(12-29)$ & & \\
\hline$<70$ & 60 & 74 & $17(12-25)$ & $0.93(0.60-1.45)$ & 0.76 \\
\hline$\geq 70$ & 31 & 37 & $17(12-24)$ & & \\
\hline Metastasis at presentation & & & & & 0.006 \\
\hline Yes & 61 & 71 & $12(8-17)$ & $1.85(1.19-2.89)$ & \\
\hline No & 30 & 40 & $25(18-44)$ & & \\
\hline$\geq 2$ metastatic sites at diagnosis & & & & & 0.02 \\
\hline Yes & 40 & 45 & $12(7-20)$ & $1.63(1.07-2.48)$ & \\
\hline No & 51 & 66 & $21(14-29)$ & & \\
\hline Lung metastasis & & & & & 0.08 \\
\hline Yes & 57 & 70 & $15(10-20)$ & $1.47(0.95-2.29)$ & \\
\hline No & 34 & 41 & $21(13-38)$ & & \\
\hline Bone metastasis & & & & & 0.76 \\
\hline Yes & 25 & 29 & $17(8-38)$ & $0.93(0.58-1.49)$ & \\
\hline No & 66 & 82 & $17(|3-2|)$ & & \\
\hline Lymph node metastasis & & & & & 0.13 \\
\hline Yes & 15 & 20 & $29(7-44)$ & $0.65(0.36-1.14)$ & \\
\hline No & 76 & 91 & $15(12-20)$ & & \\
\hline Liver metastasis & & & & & 0.0007 \\
\hline Yes & 16 & 17 & $7(3-17)$ & $2.52(1.45-4.39)$ & \\
\hline No & 75 & 94 & $21(14-29)$ & & \\
\hline Metastasectomy & & & & & 0.51 \\
\hline Yes & 18 & 23 & $2 \mid(|I-3|)$ & $0.84(0.50-I .4 I)$ & \\
\hline No & 73 & 88 & $16(12-22)$ & & \\
\hline Systemic therapy & & & & & 0.003 \\
\hline Targeted therapy & 63 & 83 & 21 (14-29) & $0.52(0.33-0.8 I)$ & \\
\hline Immunotherapy & 28 & 28 & $12(7-15)$ & & \\
\hline
\end{tabular}

Abbreviations: $\mathrm{Cl}$, confidence interval; OS, overall survival.

presentation had undergone a prior nephrectomy. Median OS was estimated at 25 months (18-44 months). Patients with metastasis at presentation and who had undergone nephrectomy ( $\mathrm{n}=49$ ) had a median OS of 18 months (9-29 months) compared to patients without nephrectomy $(n=22)$ who had a median OS of 8 months (4-12 months) (hazard ratio $=0.43$ [0.25-0.74], $P=0.002$ ).

In multivariate analysis, three prognostic factors were independent predictors of long survival: prior nephrectomy (hazard ratio $=0.38[0.22-0.64], P<0.0001$ ); systemic therapy by targeted therapy (hazard ratio $=0.50[0.31-0.80]$, $P=0.005$ ); and lack of liver metastasis (hazard ratio $=0.43$ [0.22-0.82], $P=0.002$ ) (Table 5).
Patients within a favorable MSKCC risk group had a median OS of 21 months (14-31 months) (16 deaths among 22 patients) compared to 14 months (10-20 months) for patients within an intermediate or poor MSKKC risk group (61 deaths among 72 people), but this difference was not statistically significant (hazard ratio $=0.71[0.41-1.23]$, $P=0.22)$. Interestingly, all patients of the "targeted therapy" cohort, whatever the MSKKCC risk group, had longer survival than patients of the "immunotherapy" cohort (respectively, 22 months versus 12 months for favorable MSKCC risk group $[P=0.0009]$ and 15 months versus 10 months for intermediate and poor MSKKC risk groups [ $P=0.04]$ ) (Table 6). 
Table 5 Multivariate analysis of prognostic factors of overall survival

\begin{tabular}{lll}
\hline Prognostic factors & $\begin{array}{l}\text { Hazard ratio } \\
\text { with 95\% Cl }\end{array}$ & P-value \\
\hline Prior nephrectomy & $0.38(0.22-0.64)$ & 0.000 I \\
Targeted systemic therapy & $0.50(0.31-0.80)$ & 0.005 \\
Lack of liver metastasis & $0.43(0.22-0.82)$ & 0.002 \\
Presence of lymph node metastasis & $0.72(0.39-1.35)$ & 0.25 \\
Lack of lung metastasis & $0.93(0.56-1.55)$ & 0.73 \\
One metastatic site & $0.96(0.56-1.63)$ & 0.87 \\
\hline
\end{tabular}

Abbreviation: $\mathrm{Cl}$, confidence interval.

\section{First-line systemic therapy TTF}

Median first-line systemic therapy TTF for the entire cohort of 111 patients was 7 months (95\% CI; [4-9 months]) and the 1 -year TTF was $32 \%$ (Figure 2A). A total of 105 patients had progressed. Median first-line systemic therapy TTF was 8 months (6-12 months) for patients of the "targeted therapy" cohort compared with 3 months ( $2-4$ months) for patients of the "immunotherapy" cohort (hazard ratio $=0.60$ [0.39-0.94], $P=0.02$ ) (Figure 2B).

Figure 1D shows the impact of first-line systemic therapy TTF on OS. The patients with first-line systemic therapy TTF $\geq 6$ months ( $n=60$, ie, $51 / 83$ and $9 / 28$ patients treated with targeted therapy and immunotherapy, respectively) had a median OS of 31 months (21-40 months) compared with patients with first-line therapy TTF $<6$ months $(\mathrm{n}=51)$ with a median OS of only 7 months (6-10 months) (hazard ratio $=0.30$ [0.19-0.46], $P<0.0001)$.

\section{Discussion}

Novel therapies for mccRCC bring both new hope and new challenges. To date, large controlled studies have shown significant benefit in PFS or OS with seven targeted therapies: the antiangiogenic monoclonal antibody bevacizumab associated with interferon; the oral tyrosine kinase inhibitors sunitinib, sorafenib, pazopanib, and axitinib; and the mTOR inhibitors temsirolimus and everolimus. ${ }^{27}$ Schemas, such as the one presented in Figure 3, may also be used to determine the level of evidence available for targeted agents and immunologic approach in varied clinical settings.

Questioning the impact of targeted agents in patients with metastatic RCC has led us to assess the effectiveness of these drugs in pragmatic use without patient selection. Thus, all patients with mccRCC, treated over a 10-year period in two main oncology treatment centers of the Franche-Comté region were included in this retrospective study. Our population reflects classical distribution of metastatic sites with the lung, bone, lymph nodes, and liver as the most common sites. ${ }^{28}$ In daily clinical practice, an absolute difference of 9 months in median OS was observed for patients treated with at least one targeted therapy ("targeted therapy" cohort) compared with patients treated with immunotherapy without targeted therapy ("immunotherapy" cohort) (21 months [14-29 months] versus 12 months [7-15 months], respectively, $P=0.003$ ). This benefit was confirmed in multivariate analysis. Adjusted for the prior nephrectomy and lack of liver metastasis, the risk of death was reduced by half (hazard ratio $=0.50[0.31-0.80], P=0.005)$. Interestingly, it seems that all patients, regardless of their MSKCC risk group, obtained survival benefits from the use of targeted agents ( 22 months versus 12 months within the favorable MSKCC risk group $[P=0.0009]$ and 15 months versus 10 months within the intermediate and poor MSKKC risk groups $[P=0.04]$ ). However, this benefit seems to be higher for patients within the favorable MSKCC risk group.

The benefit of prior nephrectomy on survival was confirmed for metastatic RCC at presentation or not, with a median OS of 21 months (16-29 months) versus 8 months (4-12 months) (hazard ratio $=0.32[0.19-0.53], P<0.0001)$. In metastatic RCC, two randomized trials showed a survival benefit for cytoreductive nephrectomy in selected patients before interferon therapy compared with interferon therapy

Table 6 Overall survival according to MSKCC risk group and systemic therapy

\begin{tabular}{|c|c|c|c|c|c|}
\hline & \multicolumn{2}{|c|}{ Number of patients } & \multirow{2}{*}{$\begin{array}{l}\text { Median OS (months) } \\
\text { with } 95 \% \mathrm{Cl}\end{array}$} & \multirow{2}{*}{$\begin{array}{l}\text { Hazard ratio } \\
\text { with } 95 \% \mathrm{Cl}\end{array}$} & \multirow[t]{2}{*}{$P$-value } \\
\hline & Died & Total & & & \\
\hline Entire cohort & 91 & 111 & $17(13-22)$ & I & I \\
\hline \multicolumn{6}{|c|}{ MSKCC risk group: favorable } \\
\hline Systemic therapy & & & & & 0.0009 \\
\hline Targeted therapy & 12 & 18 & $22(17-44)$ & $0.13(0.03-0.53)$ & \\
\hline Immunotherapy & 4 & 4 & $12(4-15)$ & & \\
\hline \multicolumn{6}{|c|}{ MSKCC risk group: intermediate and poor } \\
\hline Systemic therapy & & & & & 0.04 \\
\hline Targeted therapy & 45 & 56 & $15(10-24)$ & $0.55(0.31-0.98)$ & \\
\hline Immunotherapy & 16 & 16 & $10(4-16)$ & & \\
\hline
\end{tabular}

Abbreviations: $\mathrm{Cl}$, confidence interval; MSKCC, Memorial Sloan-Kettering Cancer Center; OS, overall survival. 
A

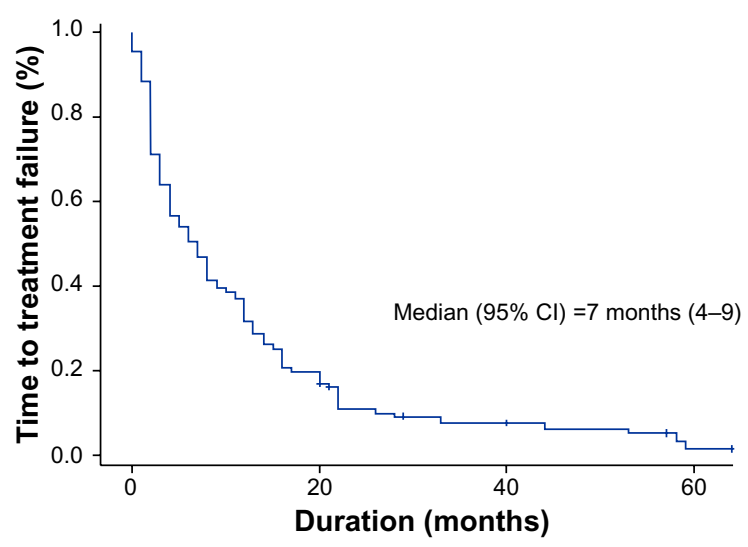

B

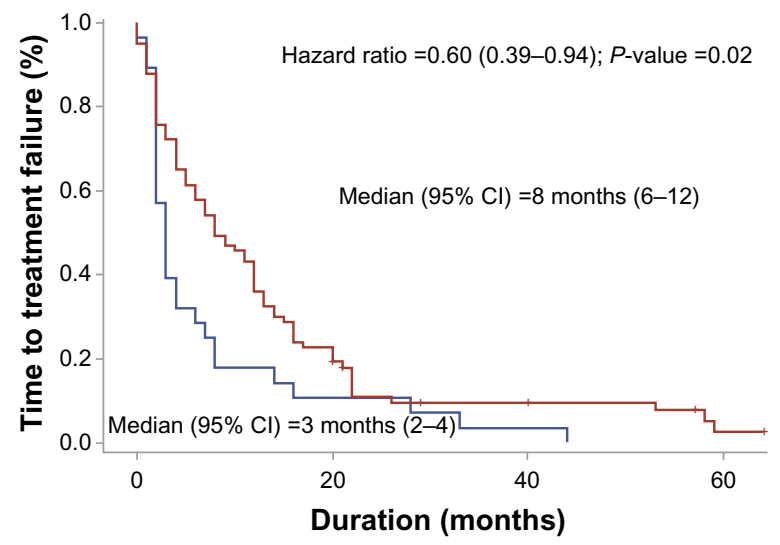

Figure 2 Kaplan-Meier estimates of first-line systemic therapy TTF.

Notes: (A) TTF for the entire cohort. (B) TTF according to the systemic therapy: "targeted therapy" (in red) versus "immunotherapy" (in blue).

Abbreviations: $\mathrm{Cl}$, confidence interval; TTF, time to treatment failure.

alone. ${ }^{11,12}$ The combined analysis of the two trials then revealed median OS of 13.6 months (9.7-17.4 months) versus 7.8 months (5.9-9.7 months) $(P=0.002)$ for nephrectomy over nonsurgery, respectively. ${ }^{11}$ However, the real impact of cytoreductive nephrectomy in this setting with targeted therapies available will be fully explored through the randomized Phase III CARMENA trial.

In our study, one metastatic site was an independent predictor of short survival: liver metastasis (hazard ratio $=2.33$ [1.22-4.45], $P=0.002)$. The negative impact of liver metastases on survival outcomes of patients treated with currently approved molecularly targeted agents has already been observed on another cohort of 2,027 patients from the International mRCC Database Consortium. ${ }^{29}$ Furthermore, in both this International mRCC Database Consortium cohort and another from the Beuselinck et al study, bone metastases were found to have a negative impact on survival. ${ }^{29,30}$ In our study, bone metastases have not been related to OS.

Median first-line systemic therapy progression-free survival (PFS) was 8 months for the "targeted therapy" cohort patients. This finding could appear lower than the results published in Phase III clinical trials, but, looking at other data, it compares favorably with the published 9.4 months of median PFS and 18.7 months of median OS from a global expanded-access of sunitinib to 4,577 patients. ${ }^{31}$ As previously described by Seidel et al and Halabi et al, our study shows an impact of first-line systemic therapy PFS on OS with a cutoff at 6 months of PFS. ${ }^{32,33}$

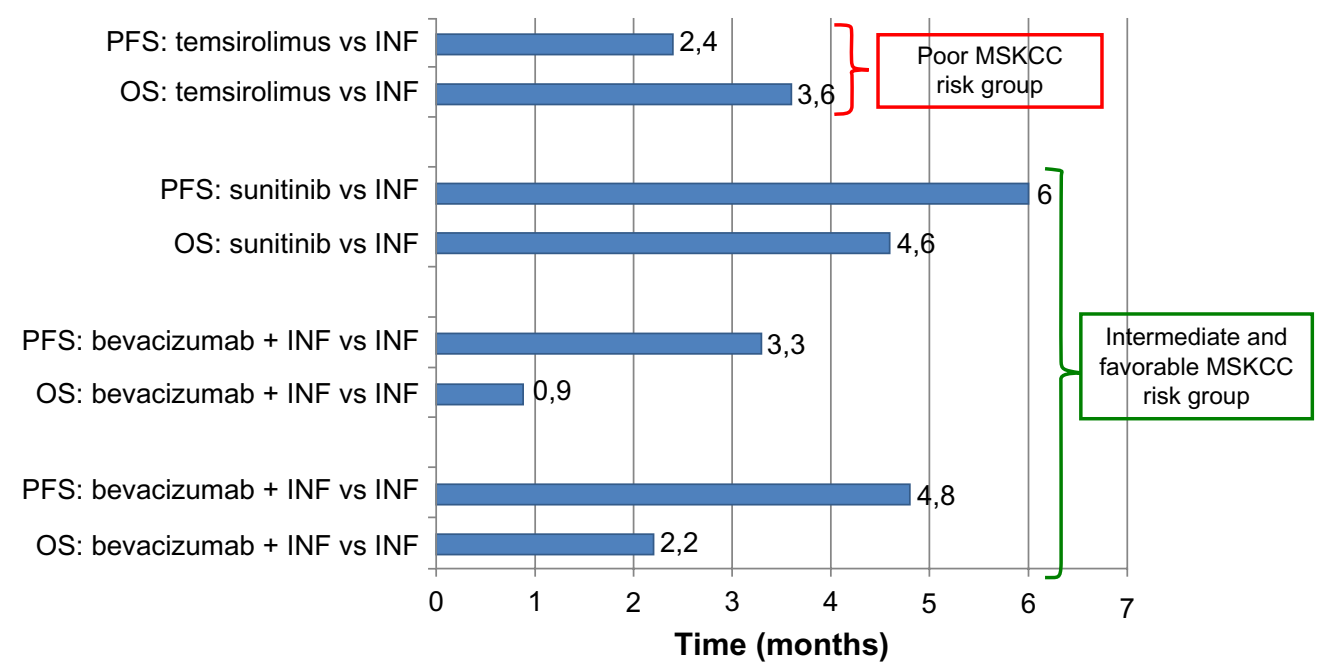

Figure 3 Absolute differences in progression-free survival and overall survival in pivotal trials where immunotherapy and targeted therapies for mRCC were compared.

Abbreviations: INF, interferon- $\alpha$; mRCC, metastatic renal cell carcinoma; MSKCC, Memorial Sloan-Kettering Cancer Center; OS, overall survival; PFS, progression-free survival; vs, versus. 
The results of the present study need to be viewed within the context of a retrospective analysis, small sample size, and lack of some data. Some factors, such as time effect, could not be taken into account. However, three previous larger studies (one national, two others multicentric) confirmed a positive impact of targeted therapies on the survival outcomes of patients with mccRCC. ${ }^{34-36}$ Moreover, recent reports have raised the question of a potential immunomodulation of targeted therapy, and immunotherapy remains an important target in this setting. ${ }^{37,38}$

\section{Conclusion}

Despite limits in our study, but in line with other publications, our results suggest that targeted therapies are associated with improved overall survival in comparison with cytokines. In the context of rational decision making in health care, a major challenge is to provide cost-effectiveness data that are relevant to daily practice and which may be used to optimize the use of healthcare resources. A pharmacoeconomic study, commonly used to evaluate the health benefit of new treatments, would allow a more precise evaluation of targeted therapy effectiveness in the clear-cell renal cell carcinoma setting and on a larger scale.

\section{Acknowledgment}

We would like to thank Ms Pamela Albert for English assistance in the correction of the manuscript.

\section{Disclosure}

DrThiery-Vuillemin serves as a consultant for Novartis, Pfizer, Roche. The authors report no other conflicts of interest.

\section{Reference}

1. INCa. Epidémiologie des cancers en France métropolitaine - Incidence et mortalité. 2011. Available from: http://www.e-cancer.fr/. Accessed September 15, 2013.

2. Albouy B, Gross Goupil M, Escudier B, Massard C. [Renal cell carcinoma management and therapies in 2010]. Bull Cancer. 2010;97:17-28. French.

3. Beck SD, Patel MI, Snyder ME, et al. Effect of papillary and chromophobe cell type on disease-free survival after nephrectomy for renal cell carcinoma. Ann Surg Oncol. 2004;11(1):71-77.

4. Lipworth L, Tarone RE, McLaughlin JK. The epidemiology of renal cell carcinoma. J Urol. 2006;176(6 Pt 1):2353-2358.

5. Motzer RJ, Bacik J, Murphy BA, Russo P, Mazumdar M. Interferonalfa as a comparative treatment for clinical trials of new therapies against advanced renal cell carcinoma. J Clin Oncol. 2002;20(1): 289-296.

6. Lam JS, Bergman J, Breda A, Schulam PG. Importance of surgical margins in the management of renal cell carcinoma. Nat Clin Pract Urol. 2008; 5(6):308-317.

7. Downs TM, Schultzel M, Shi H, Sanders C, Tahir Z, Sadler GR. Renal cell carcinoma: risk assessment and prognostic factors for newly diagnosed patients. Crit Rev Oncol Hematol. 2009;70(1):59-70.
8. Moch H, Artibani W, Delahunt B, et al. Reassessing the current UICC/ AJCC TNM staging for renal cell carcinoma. Eur Urol. 2009;56(4): 636-643.

9. National Comprehensive Cancer Network. Clinical Practice Guidelines in Oncology (NCCN Guidelines ${ }^{\circledR}$ ) version 2. 2010. Accessed April 02, 2013.

10. Janzen NK, Kim HL, Figlin RA, Belldegrun AS. Surveillance after radical or partial nephrectomy for localized renal cell carcinoma and management of recurrent disease. Urol Clin North Am. 2003;30(4): $843-852$.

11. Flanigan RC, Salmon SE, Blumenstein BA, et al. Nephrectomy followed by Interferon alfa-2b compared with interferon alfa- $2 \mathrm{~b}$ alone for metastatic renal-cell cancer. $N$ Engl J Med. 2001;345(23):1655-1659.

12. Mickisch GH, Garin A, van Poppel H, et al; European Organisation for Research and Treatment of Cancer (EORTC) Genitourinary Group. Radical nephrectomy plus interferon-alfa-based immunotherapy compared with interferon alfa alone in metastatic renal-cell carcinoma: a randomised trial. Lancet. 2001;358(9286):966-970.

13. Oudard S, George D, Medioni J, Motzer R. Treatment options in renal cell carcinoma: past, present and future. Ann Oncol. 2007;18 Suppl 10:x25-x31.

14. Choueiri TK, Vaziri SA, Jaeger E, et al. von Hippel-Lindau gene status and response to vascular endothelial growth factor targeted therapy for metastatic clear cell renal cell carcinoma. J Urol. 2008;180(3):860-865.

15. Rini BI. Vascular endothelial growth factor-targeted therapy in metastatic renal cell carcinoma. Cancer. 2009;115:2306-2312.

16. Mansi L, Thiery-Vuillemin A, Nguyen T, et al. Safety profile of new anticancer drugs. Expert Opin Drug Saf. 2010;9(2):301-317.

17. Thomas GV, Tran C, Mellinghoff IK, et al. Hypoxia-inducible factor determines sensitivity to inhibitors of mTOR in kidney cancer. Nat Med. 2006;12(1):122-127.

18. Escudier B, Eisen T, Stadler WM, et al; TARGET Study Group. Sorafenib in advanced clear-cell renal-cell carcinoma. $N$ Engl J Med. 2007;356(2):125-134.

19. Escudier B, Pluzanska A, Koralewski P, et al; AVOREN Trial investigators. Bevacizumab plus interferon alfa-2a for treatment of metastatic renal cell carcinoma: a randomised, double-blind phase III trial. Lancet. 2007;370(9605):2103-2111.

20. Motzer RJ, Hutson TE, Tomczak P, et al. Sunitinib versus interferon alfa in metastatic renal-cell carcinoma. N Engl J Med. 2007;356(2): 115-124.

21. Hudes G, Carducci M, Tomczak P, et al; Global ARCC Trial. Temsirolimus, interferon alfa, or both for advanced renal-cell carcinoma. N Engl J Med. 2007;356(22):2271-2281.

22. Motzer RJ, Escudier B, Oudard S, et al; RECORD-1 Study Group. Efficacy of everolimus in advanced renal cell carcinoma: a double-blind, randomised, placebo-controlled phase III trial. Lancet. 2008;372(9637): $449-456$.

23. Rini BI, Escudier B, Tomczak P, et al. Comparative effectiveness of axitinib versus sorafenib in advanced renal cell carcinoma (AXIS): a randomised phase 3 trial. Lancet. 2011;378(9807):1931-1939.

24. Sternberg CN, Davis ID, Mardiak J, et al. Pazopanib in locally advanced or metastatic renal cell carcinoma: results of a randomized phase III trial. J Clin Oncol. 2010;28(6):1061-1068.

25. Motzer RJ, Bacik J, Mariani T, Russo P, Mazumdar M, Reuter V. Treatment outcome and survival associated with metastatic renal cell carcinoma of non-clear-cell histology. J Clin Oncol. 2002;20(9):2376-2381.

26. Motzer RJ, Molina AM. Targeting renal cell carcinoma. J Clin Oncol. 2009;27(20):3274-3276.

27. National Comprehensive Cancer Network Clinical Practice Guidelines in Oncology, Kidney Cancer version 1, 2013. Accessed April 02, 2013.

28. Bianchi M, Sun M, Jeldres C, et al. Distribution of metastatic sites in renal cell carcinoma: a population-based analysis. Ann Oncol. 2012;23(4):973-980.

29. McKay RR, Kroeger N, Xie W, et al. Impact of bone and liver metastases (BM, LM) in patients with metastatic renal cell carcinoma (mRCC) treated with molecularly targeted agents (MTAs): Results from the International mRCC Database Consortium (IMDC). J Clin Oncol. 2013 Genitourinary Cancers Symposium. Abstract 394. 
30. Beuselinck B, Oudard S, Rixe O, et al. Negative impact of bone metastasis on outcome in clear-cell renal cell carcinoma treated with sunitinib. Ann Oncol. 2011;22:794-800.

31. Gore ME, Porta C, Bracarda S, et al. Sunitinib global expanded access trial in metastatic renal cell carcinoma (mRCC) - Final results ESMO 2012 Abstract 820P.

32. Seidel C, Fenner M, Reuter CW, et al. Progression-free survival (PFS) of first-line VEGF-targeted therapy as a prognostic parameter for overall survival (OS) in patients with metastatic renal cell carcinoma (mRCC). 2011 ASCO Annual Meeting Abstract 4591.

33. Halabi S, Rini BI, Stadler WM, et al. Use of progression-free survival (PFS) to predict overall survival (OS) in patients with metastatic renal cell carcinoma (mRCC). 2010 ASCO Annual Meeting Abstract 4525.

34. Shek D, Tomlinson B, Brown M, Brunson A, Pan CX, Lara PN Jr. Epidemiologic trends in renal cell carcinoma in the cytokine and postcytokine eras: a registry analysis of 28,252 patients. Clin Genitourin Cancer. 2012;10(2):93-98.
35. Wahlgren T, Harmenberg U, Sandström P, et al. Treatment and overall survival in renal cell carcinoma: a Swedish population-based study (2000-2008). Br J Cancer. 2013;108:1541-1549.

36. Soerensen AV, Donskov F, Hermann GG, et al. Implementation of targeted therapy in Denmark for patients with metastatic renal cellcarcinoma: results from the Danishrenal cancer group (DARENCA) study-2. ESMO 2012 Abstract 819P.

37. Adotevi O, Pere H, Ravel P, et al. A decrease of regulatory T cells correlates with overall survival after sunitinib-based antiangiogenic therapy in metastatic renal cancer patients. J Immunother. 2010;33(9):991-998.

38. Thiery-Vuillemin A, Mansi L, Laheurte C, et al. Modulation of Regulatory $\mathrm{T}$ cells in long responsive patients with metastatic renal cell carcinoma (mRCC) treated with everolimus (EVE). ECCO 2013 abstract 2801 .
OncoTargets and Therapy

\section{Publish your work in this journal}

OncoTargets and Therapy is an international, peer-reviewed, open access journal focusing on the pathological basis of all cancers, potential targets for therapy and treatment protocols employed to improve the management of cancer patients. The journal also focuses on the impact of management programs and new therapeutic agents and protocols on

\section{Dovepress}

patient perspectives such as quality of life, adherence and satisfaction The manuscript management system is completely online and includes a very quick and fair peer-review system, which is all easy to use. Visit http://www.dovepress.com/testimonials.php to read real quotes from published authors.

Submit your manuscript here: http://www.dovepress.com/oncotargets-and-therapy-journal 